\title{
Corrigendum
}

\section{A new model for parent-of-origin effect analyses applied to Brown Swiss cattle slaughterhouse data - CORRIGENDUM}

\author{
I. Blunk, M. Mayer, H. Hamann and N. Reinsch
}

doi:10.1017/S1751731116002391, published by Cambridge University Press, 6 December 2016.

In the article by Blunk et al. (2017), presented in Animal, inadvertent mistakes were made. This concerns the formula used to calculate the reliabilities of estimated parent-of-origin effects (POE), where the factor of $1 / 2$ in the denominator has been omitted. The correct formula should read:

$$
r^{2}=1-\frac{\mathrm{PEV}}{1 / 2 \sigma_{i}^{2}\left(1+\mathrm{F}_{i}\right)},
$$

where $F_{i}$ is the inbreeding coefficient of ancestor $i$.

Therefrom, reliabilities had to be calculated, which led to a number of changes (highlighted in bold letters) in the different chapters of the manuscript, as outlined below. All other results and conclusions remain, however, unchanged.

In the Abstract it is stated that the reliabilities of POE ranged between 0.4 and 0.9 . However, the recalculation of reliabilities according to the formula above led to reliabilities ranging between zero and 0.9 .

With regard to the chapter 'Reliability of parent-of-origin effects and genetic trends', the recalculated reliabilities of the POE are summarised in the following table:

Table Range and average of the reliabilities recalculated for the parent-of-origin effects predicted for the net BW gain, fat score and conformation class

\begin{tabular}{lcccc}
\hline \hline & \multicolumn{2}{c}{ reliabilities (range) } & & \multicolumn{2}{c}{ reliabilities (average) } \\
\cline { 2 - 3 } Trait & sires & dams & sires & dams \\
\hline Net BW gain & $0.09-0.82$ & $0.00-0.91$ & 0.27 & 0.29 \\
Fat score & $0.00-0.84$ & $0.00-0.42$ & 0.11 & 0.10 \\
Fat score & $0.00-0.87$ & $0.00-0.45$ & 0.13 & 0.12 \\
Conformation $^{1}$ & $0.00-0.79$ & $0.00-0.39$ & 0.09 & 0.08 \\
Conformation $^{1}$ & $0.00-0.88$ & $0.00-0.47$ & 0.14 & 0.13 \\
\hline \hline
\end{tabular}

${ }^{1}$ Treated as ordered categorical traits using a generalized linear mixed model.

Moreover, in this chapter differences in the average reliabilities of sires were shown depending on the number of their progeny. The reliabilities were recalculated according to the formula above so that sires with differences in the average reliability for the estimated POE on the net BW gain had the following average numbers of sons, daughters and maternal grandsons:

\begin{tabular}{llll}
\hline \hline$r^{2}<0.30$ & 0.74 & 11.31 & 4.86 \\
$0.30 \leq r^{2} \leq 0.40$ & 0.96 & 17.47 & 9.37 \\
$r^{2}>0.40$ & 3.57 & 37.67 & 7.87 \\
\hline \hline
\end{tabular}




\section{Corrigendum}

Further, the reliabilities in Figure 1 needed to be adjusted:

(a)

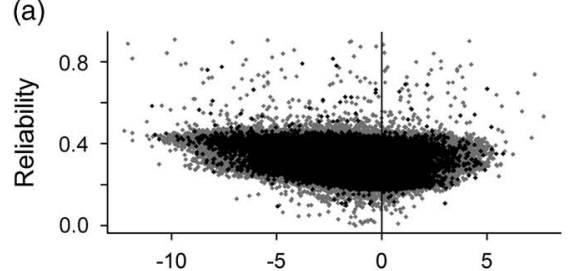

(c)

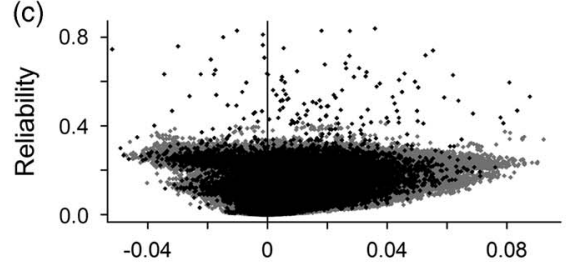

(e)

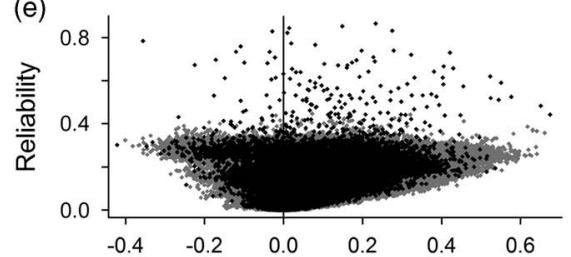

(g)

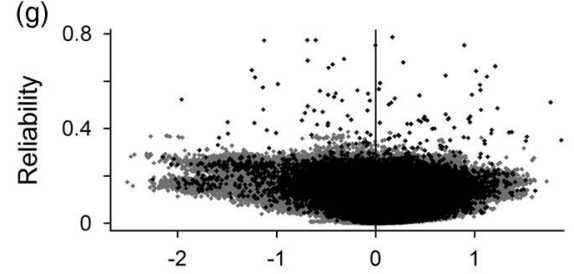

(i)

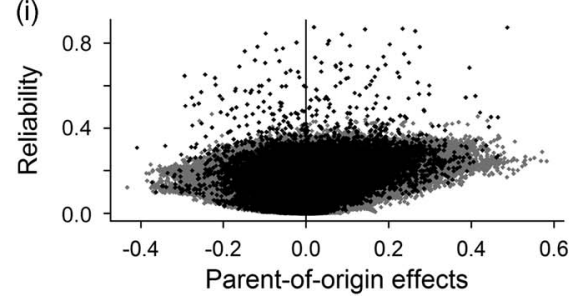

(b)

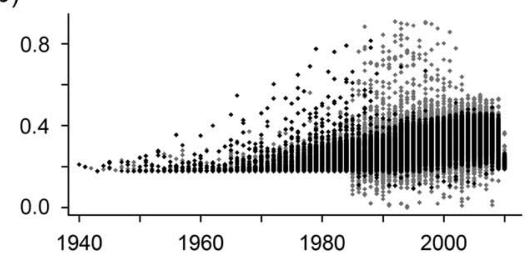

(d)

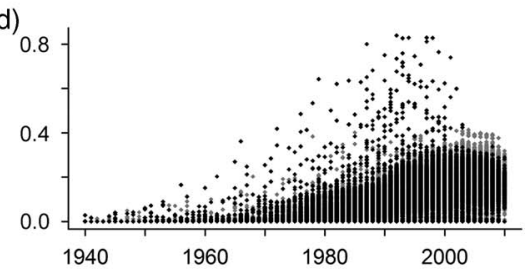

(f)

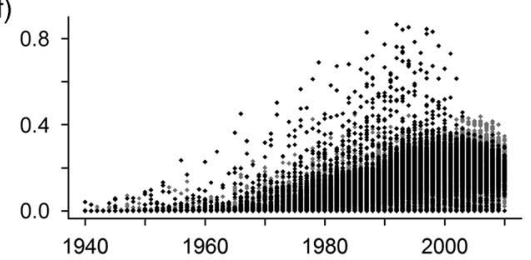

(h)

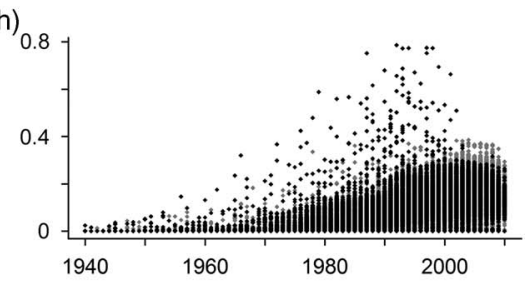

(j)

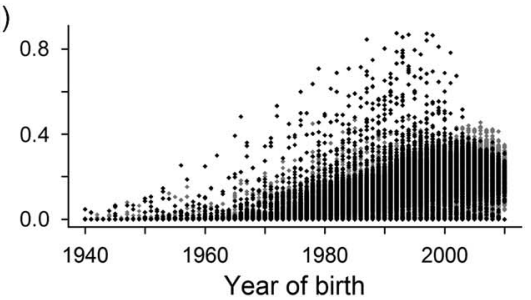

Figure 1 Parent-of-origin effects for sires (black) and dams (grey) relative to their reliability (left side), as well as their reliability relative to the year of birth (right side). Parent-of-origin effects were estimated using a linear mixed model for the net BW gain (g/days) (a, b), fat score (c, d) and conformation class $(g, h)$. Parent-of-origin effects were estimated using a generalised linear mixed model for the fat score (e, f) and conformation class (i, j).

The authors apologise for the error.

\section{References}

Blunk I, Mayer M, Hamann H and Reinsch N 2017. A new model for parent-of-origin effect analyses applied to Brown Swiss cattle slaughterhouse data. Animal 11, 1096-1106. 